\title{
ESTUDO DA EFICIÊNCIA DE CLASSIFICAÇÕES SUPERVISIONADAS APLICADAS EM IMAGEM DE MÉDIA RESOLUÇÃO ESPACIAL
}

\author{
STUDY OF THE EFFICIENCY OF SUPERVISIONED CLASSIFICATIONS APPLIED IN MEDIUM IMAGE \\ SPATIAL RESOLUTION
}

\author{
Carla Talita Pertille ${ }^{1}$, Gabriela Oliveira Silva², Camila Furlan de Souza ${ }^{3}$, Marcos Felipe Nicoletti $^{4}$ \\ 1, 2, 3, 4 Universidade do Estado de Santa Catarina, Lages, Santa Catarina, Brasil - \\ mes.florestal@gmail.com,gabriela.utfpr@gmail.com,camilafurlan.florestal@gmail.com \& \\ marcos.nicoletti@udesc.br
}

RESUMO

\begin{abstract}
A aplicação de técnicas de Sensoriamento Remoto na classificação do uso da terra de um município possibilita melhor gestão e planejamento geográfico. Nessa temática, o objetivo desta pesquisa foi identificar o melhor algoritmo de classificação supervisionada para o mapeamento do uso e cobertura da terra para o município de São José do Cerrito - Santa Catarina. Para tanto, foi utilizada uma imagem orbital do sensor Sentinel-2/MSI. Após o pré-processamento digital da imagem, foram definidas como classes de uso e cobertura da terra: agricultura, área urbana, corpos hídricos e vegetação. Posteriormente, as amostras de treinamento e validação foram geradas para cada classe. Os métodos de classificação supervisionados (Maximum Likelihood Classification - Máxima Verossimilhança - MaxVer) e (Suppor Vector Machine Classification - Máquinas de Vetor de Suporte - SVM), (Neural Net Classification - Redes Neurais RNA) e (Minimum Distance Classification - Mínima distância - MND) foram testados. Por fim, calcularam-se as estatísticas de acurácia da classificação para cada método, tais como: índice Kappa, exatidão global, coeficiente Tau, erros de omissão e comissão e exatidão ao usuário e ao produtor. De maneira geral, todos os métodos propiciaram elevados valores do índice Kappa (MaxVer $(0,9760)$, SVM $(0,9616)$, RNA $(0,9880)$ e MND $(0,9244)$ ). As estatísticas para o classificador testado revelaram que o método com o melhor desempenho foi o RNA, seguido do MaxVer, SVM e MND. De maneira geral, todas as técnicas de classificação supervisionada testadas foram efetivas no mapeamento de uso da terra do município de São José do Cerrito - SC, mas o método mais eficiente foi o RNA, com índice Kappa de 0,9880 e acurácia global de $99,33 \%$.
\end{abstract}

PALAVRAS-CHAVE: Algoritmos, Mapeamento, Sentinel-2.

\section{ABSTRACT}

The application of Remote Sensing techniques in the classification of the land use of a municipality allows a single form of management and geographic planning. In this subject, the aim of this study was to identify the best supervised classification algorithm for land use and land cover mapping for the municipality of São José do Cerrito - Santa Catarina. For that, an orbital image of Sentinel-2 / MSI sensor was used. After digital image processing, land use and land cover classes were defined as: agriculture, urban area, water bodies and vegetation. Subsequently, the training and validation samples were generated for each class. The Maximum Likelihood Classification (MaxVer) and Suppor Vector Machine Classification (SVM), Neural Net Classification (RNA) and Minimum Distance Classification - (MND) were tested. Finally, we calculated the classification accuracy statistics for each method, such as: Kappa index, global accuracy, Tau coefficient, omission and commission errors, and user and producer accuracy. In general, all the methods provided an excellent classification according to the Kappa index, MaxVer (0.9760), SVM (0.9616), RNA (0.9880) and MND (0.9244). The statistics for tested classifier revealed that the method with the best performance was RNA, followed by MaxVer, SVM and MND. In general, all the supervised classification techniques tested were effective in the mapping of the soil use of the city of São José do Cerrito - SC, but the most efficient method was Artificial Neural Networks (RNA), with a Kappa index of 0.9880 and overall accuracy of $99.33 \%$.

KEYWORDS: Algorithms, Mapping, Sentinel-2. 


\section{INTRODUÇÃO}

As mudanças de uso e cobertura da terra são importantes para diferentes aplicações ambientais e de mapeamento. O levantamento de informações e o monitoramento das alterações de uso e cobertura da terra são imprescindíveis para a compreensão das dinâmicas das mudanças globais, além da modelagem de seus impactos no meio ambiente (ROSAN \& ALCANTÂRA, 2016).

As técnicas de Sensoriamento Remoto, têm se destacado em pesquisas que avaliam as mudanças ocorridas na cobertura e uso da terra (LI et al., 2014). Essas técnicas permitem a observação da Terra por meio de sensores remotos, possibilitando a aquisição de dados sobre grandes extensões geográficas, além de possibilitar melhor acurácia no mapeamento do uso e cobertura da terra por meio de sensores orbitais com resoluções espaciais médias e altas (ANDERSON, 2004).

A utilização de imagens orbitais para processos de classificação automática tem como aplicações: modelagem de carbono, mudança na cobertura e uso da terra, monitoramento e gerenciamento de florestas (ZHU et al., 2012). Os referidos autores também sugerem alguns classificadores para avaliar as variações ocorridas na cobertura da terra de uma área, como os paramétricos Máxima Verossimilhança (Maximum Likelihood Classification) e Mínima Distância (Minimum Distance Classification) e os não paramétricos, Redes Neurais Artificiais (Neural Net Classification) e Máquinas de Vetor de Suporte (Support Vector Machine Classification).

Os estudos de mudanças de uso e cobertura da terra retratam as formas e dinâmicas de ocupação, sendo uma grande ferramenta para o planejamento e para a tomada de decisões acerca das análises e avaliação de impactos ambientais decorrente das mudanças na cobertura vegetal. Essas pesquisas favorecem o entendimento do monitoramento da cobertura vegetal e sua relação com fatores causadores de mudanças (ANDERSON, 2004), a influência da cobertura da terra na configuração de áreas queimadas (LIMA, 2013) e modelagem e simulação das mudanças da paisagem (SOARES FILHO, 2001),

Para o monitoramento dessas mudanças a partir de dados de Sensoriamento Remoto, diversos sensores remotos já foram utilizados, como a constelação de satélites Landsat, pela resolução espacial e temporal que permitem as análises das mudanças de uso e cobertura da terra em escalas cartográficas médias. Contudo, um sensor com grande potencial de utilização nesses estudos referese a missão de satélites Sentinel-2, produzida pela Agência Espacial Europeia (European Space Agency - ESA) em função da geração de dados gratuitos, resolução espacial comparável com a de sensores comerciais, capacidade espectral (13 bandas) e temporal (5 a 10 dias) (ESA, 2010).

A aplicação de técnicas de Sensoriamento Remoto para a classificação do uso da terra de municípios vem demonstrando eficiência para o planejamento e a gestão urbana e rural. Contudo, grande maioria dos municípios não fazem uso das técnicas de Sensoriamento Remoto, tão pouco utilizam uma base de dados geográficos. Uma forma de preencher essa coluna refere-se à utilização de imagens orbitais e métodos de classificação supervisionada para construir uma base de dados integrados com Sistemas de Informação Geográfica (SIG).

Nesse cenário, o objetivo dessa pesquisa foi identificar o melhor algoritmo de classificação supervisionada para o município de São José do Cerrito - SC utilizando uma imagem do sensor orbital Sentinel-2, assim apresentando uma ferramenta rápida e viável para a determinação das classes de uso da terra, oferecendo uma solução para os problemas supracitados e também facilitar a administração da região.

\section{MATERIAL E MÉTODOS}

A pesquisa foi desenvolvida no município de São José do Cerrito, localizado na Serra Catarinense (Figura 1) com área de 94.419,15 ha e latitude de $27^{\circ} 39^{\prime} 47^{\prime \prime}$ Sul e longitude $50^{\circ} 34^{\prime} 48^{\prime \prime}$ Oeste. A altitude é de $879 \mathrm{~m}$ e o clima é classificado por Köppen como mesotérmico úmido, com temperatura média de $21,5^{\circ} \mathrm{C}$ e precipitação pluviométrica média anual de 1.640 mm (ALVARES et al. 2013).

Foi adquirida uma imagem multiespectral do sensor Sentinel-2A/MSI no portal Copernicus Access Open Hub (2017), com órbita/ponto 221/079, com data de 11/11/2017. o processamento digital dessa imagem envolveu calibração, normalização radiométrica e correção atmosférica utilizando o algoritmo Sen2Cor disponível no aplicativo computacional SNAP (Sentinel Application Platform) (ESA, 2018).

A correção atmosférica foi feita a partir do algoritmo Sen2Cor, o qual extrai as informações da profundidade óptica de aerossol baseado no método da vegetação densa e escura (KAUFMAN et al., 1997) e do vapor d'água utilizando as bandas $8 \mathrm{~A}(865 \mu \mathrm{m})$ e $9(945 \mu \mathrm{m})$ do Sentinel2. Parâmetros atmosféricos, de iluminação solar e geográficos da cena são utilizados para a finalidade de correção atmosférica baseado em Look-up Tables geradas do modelo de transferência radiativa LibRadtran. Todas as bandas foram reamostradas para $10 \mathrm{~m}$ utilizando a ferramenta resampling, presente no SNAP (ESA, 2018). 

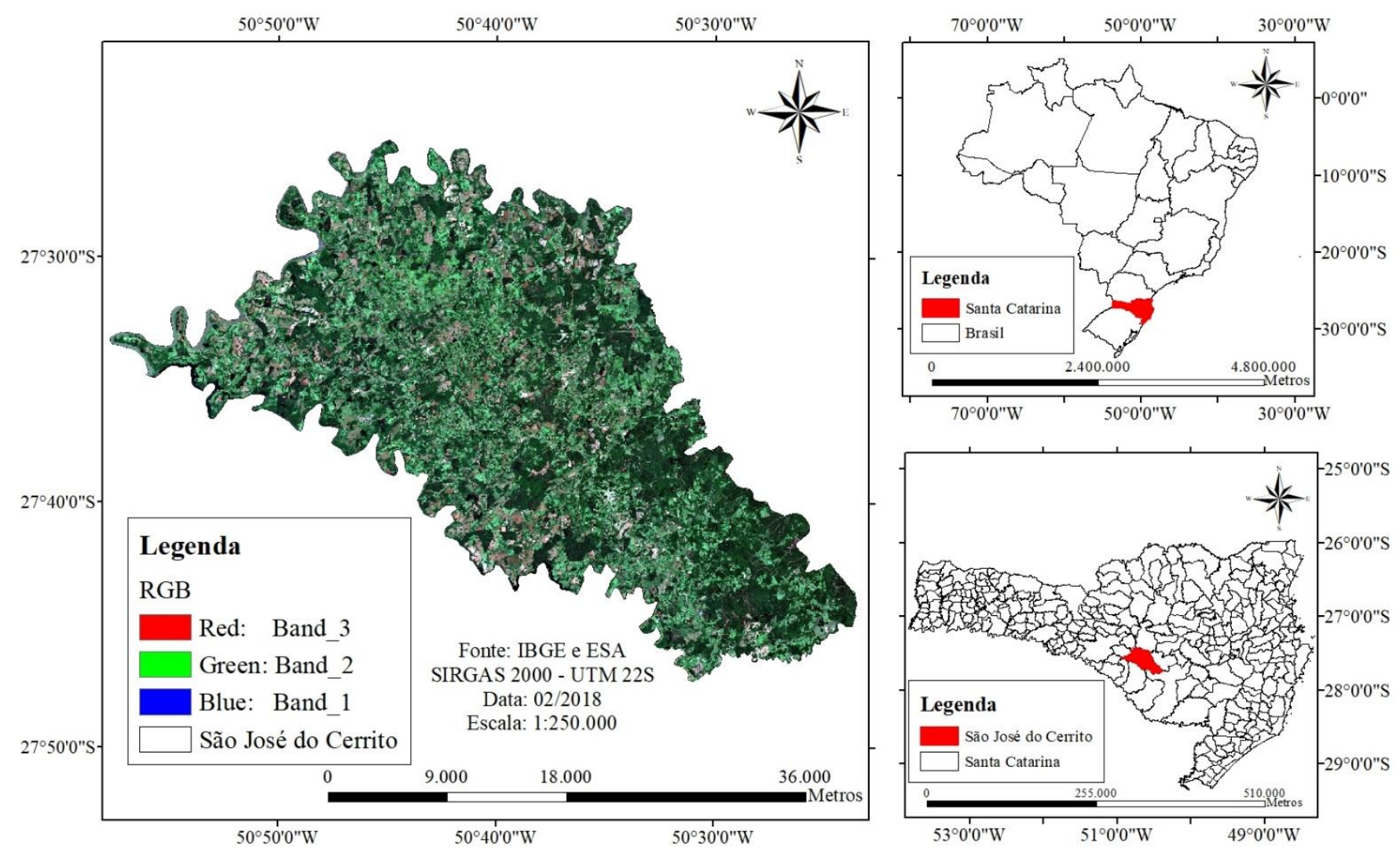

Figura 1. Localização da área de estudo referente ao município de São José do Cerrito, Sul do Brasil. Composição colorida verdadeira RGB: 492; 559; $665 \mu \mathrm{m}$ do MSI - Sentinel 2A). A imagem foi adquirida em 11/11/2017.

O shapefile do município foi obtido no portal do IBGE (Instituto Brasileiro de Geografia e Estatística) no sistema de referência SIRGAS 2000 (Sistema de Referência Geocêntrico para as Américas) na escala de 1/50.000. Para a geração das amostras, as seguintes classes de uso e cobertura da terra foram definidas a partir da visualização das feições observadas na combinação de bandas RGB (Red-Green-Blue), 4(R): $492 \mu \mathrm{m} ; 3(\mathrm{G}): 559 \mu \mathrm{m}$ e 2(B): 665 $\mu \mathrm{m}$.

Para a geração das amostras, as seguintes classes de uso e cobertura da terra foram definidas de acordo com IBGE (2013), a partir da visualização das feições observadas na combinação de bandas RGB (Red-Green-Blue), 4 (R): 492 $\mu \mathrm{m} ; 3(\mathrm{G}): 559 \mu \mathrm{m}$ e 2(B): $665 \mu \mathrm{m}$.

- Agricultura: Inclui todas as terras cultivadas, caracterizadas pelo delineamento de áreas cultivadas ou em descanso (lavouras temporárias, lavouras permanentes, pastagens plantadas, silvicultura e áreas comprovadamente agrícolas cujo uso não foi identificado no período do mapeamento).

- Área urbana: Como situação urbana foram consideradas as áreas correspondentes às cidades (sedes municipais), às vilas (sedes distritais) e às áreas urbanas isoladas.

- Corpos Hídricos: áreas ocupadas por rios, lagos, cursos d'água;

- Vegetação: abrange todos os tipos de vegetação (nativa e plantada) em todos os estágios de sucessão e pastagens e culturas agrícolas.

Com as classes definidas, o próximo passo envolveu a geração de amostras. Para isso, coletou-se 60 pontos distribuídos em toda a imagem para cada classe, totalizando assim, 300 pontos. As amostras foram divididas em $60 \%$ para treinamento e $40 \%$ para validação utilizando a ferramenta Generate Random Sample Using Ground Truth ROIs, no aplicativo computacional ENVI (Environment for Visualizing Images) (EXELIS, 2018).

Utilizando a composição de bandas RGB, os métodos de classificação supervisionados (Maximum Likelihood Classification - Máxima Verossimilhança - MaxVer) e (Suppor Vector Machine Classification - Máquinas de Vetor de Suporte - SVM), (Neural Net Classification - Redes Neurais Artificiais) e (Minimum Distance Classification Mínima distância - MND) foram testados no ENVI (EXELIS, 2018). Os mapas temáticos foram elaborados em ambiente SIG (ESRI, 2018). 
A verificação da acurácia da classificação dos métodos avaliados foi feita considerando a matriz de erro, definida por Congalton (1991), como o agrupamento de valores formados por linhas e colunas, que por sua vez, estabelecem o número de unidades de cada classe amostrada. Foram calculados o índice Kappa, exatidão global, coeficiente Tau, erros de omissão e comissão e exatidão ao usuário e ao produtor.

A aptidão do mapa foi avaliada de acordo com os valores do Índice Kappa interpretados por Landis e Koch (1977)

\section{RESULTADOS E DISCUSSÃO}

A estatística das amostras utilizadas nos métodos supervisionados revelou que a performance de cada algoritmo foi diferente em relação aos índices Kappa e Exatidão global. Todos os métodos de classificação obtiveram boa resposta quanto à representatividade das classes, sendo que o método RNA alcançou os melhores resultados: índice Kappa de 0,9880 e exatidão global de 99,33\% (Figura 2).

O menor índice Kappa foi obtido pelo método de mínima distância, além de apresentar os maiores erros de omissão e comissão. No caso dos erros de comissão, observou-se áreas que foram incluídas em uma classe à qual não pertencem, enquanto os erros de omissão se referem a áreas que pertencem a determinada classe, porém foram incluídas em outra classe. Por tais motivos, esse método apresentou a pior classificação.

Pela análise da Figura 2, as classes foram bem representadas no resultado da classificação. Contudo, em alguns pontos da imagem, houve confusão na determinação das classes área urbana e agricultura. Isso pode estar relacionado com as amostras de treinamento geradas e com a resolução espacial e espectral da imagem orbital. Além disso, a assinatura espectral dos alvos relacionados a área urbana na imagem foi similar à de agricultura em determinados locais. As classes corpos hídricos e vegetação foram representadas adequadamente, ao passo que os pixels classificados incorretamente foram pouco expressivos, não comprometendo a qualidade do mapeamento.

O método de MaxVer (Figura 3) apresentou desempenho semelhante ao RNA, contudo, houve equívoco em algumas regiões para as classes de vegetação e agricultura, bem como de área urbana com agricultura. Tal fato pode ser explicado por vegetação e agricultura compreenderem formações vegetativas. Embora essas classes tenham elementos diferentes, não ocorre uma separação precisa entre elas. Essa confusão também aconteceu no estudo de Rex et al. (2018), o qual avaliou o potencial de imagens do satélite Sentinel-2/MSI para classificação do uso e cobertura da terra de forma não supervisionada através do algoritmo cluster.

Ainda para o método de MaxVer (Figura 3), a classe corpos hídricos obteve a melhor representatividade, enquanto em alguns locais a agricultura foi confundida com área urbana. Com isso, a classe de área urbana apresentou a maior extensão, ao passo que as classes de corpos hídricos e vegetação receberam a menor representatividade.

Da mesma forma que os outros métodos, o SVM (Figura 4) apresentou erros na representação das classes área urbana e agricultura. Alguns pixels pertencentes à vegetação foram representados como corpos hídricos. Por isso, as classes de corpos hídricos e de área urbana ocuparam a maior área, ao passo que as áreas das classes de agricultura e vegetação foram inferiores.

O mapeamento obtido pelo método de mínima distância (Figura 5) foi inferior aos métodos anteriores em função da maior taxa de erros causada pelos enganos na representação de todas as classes. Ao contrário dos outros classificadores, todas as classes foram confundidas, o que gerou extensões maiores da classe área urbana e menores de agricultura.

É visualmente perceptível que a classe com a maior extensão territorial compreende a vegetação (florestas e áreas agrícolas), com valores superiores a $48 \%$ em todos os métodos. Em seguida, a agricultura ocupa mais de $20 \%$, a classe de área urbana com mais de $5 \%$ e, por fim, corpos hídricos com menos de $5 \%$. O método mais acurado de classificação (RNA) indica que 38,64\% da área do município pertence as áreas relacionadas as classes de agricultura e área urbana e que as demais classes ocupam $61,36 \%$.

Outras pesquisas também comprovaram a superioridade do método RNA. Ao comparar a eficiência de redes neurais artificiais com o classificador MaxVer para a classificação do uso das terras, com ênfase nos níveis de degradação das pastagens, em Minas Gerais, Chagas et al. (2009) concluíram que o classificador baseado nas redes neurais produziu exatidão na classificação geral e superior ao MaxVer, devido a arquitetura de rede utilizada.

A qualidade de um mapa digital de solos confeccionado a partir de covariáveis ambientais com relação significativa com a distribuição dos solos na área, por meio da aplicação de RNA foi avaliada por Arruda et al. (2013). Os resultados apontaram que a utilização de RNAs foi eficiente e que a extrapolação do conhecimento adquirido pela abordagem gerou resultados coerentes com a realidade de campo. 


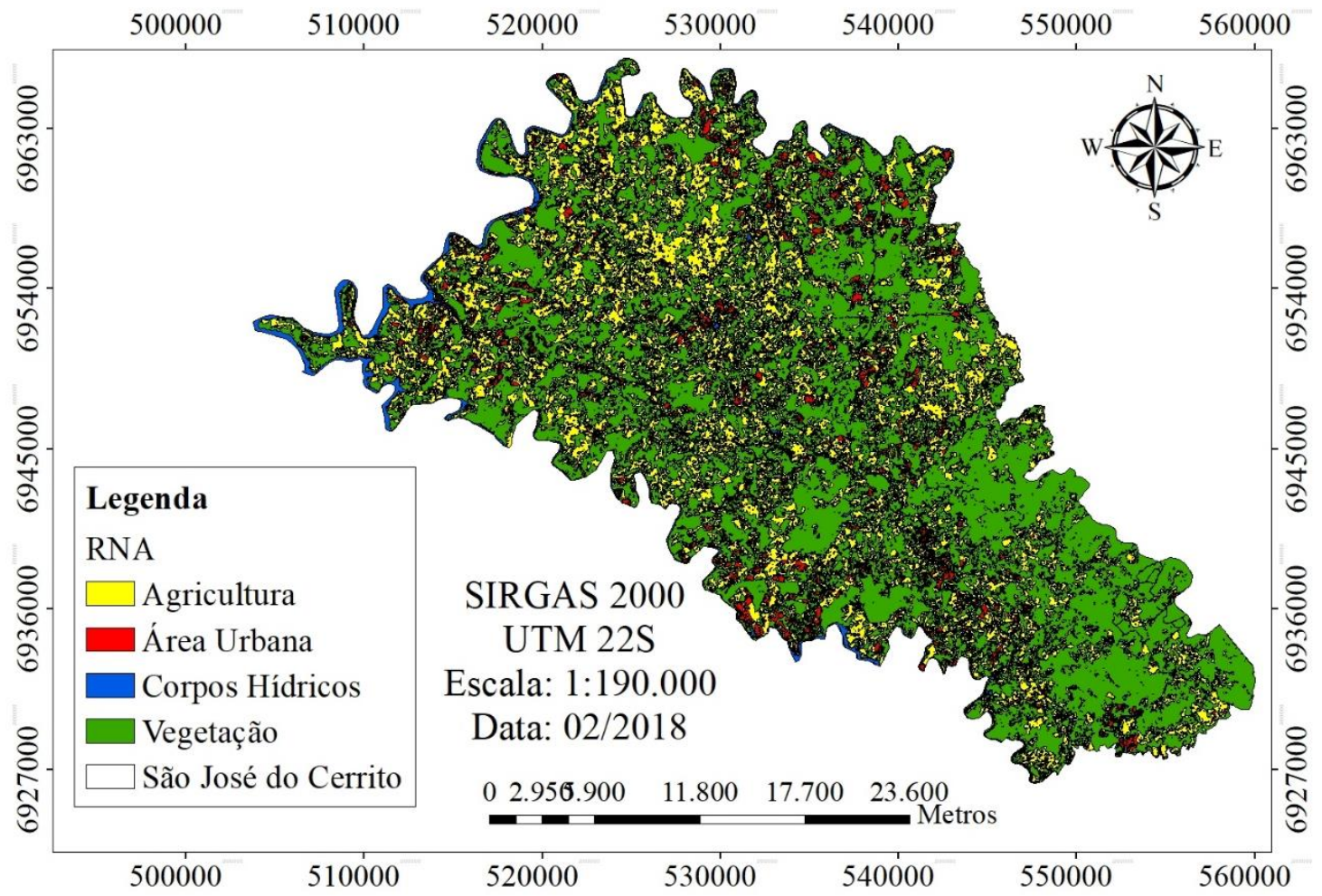

Figura 2. Classificação do uso e cobertura da terra do município de São José do Cerrito - SC pelo método Redes Neurais Artificiais.

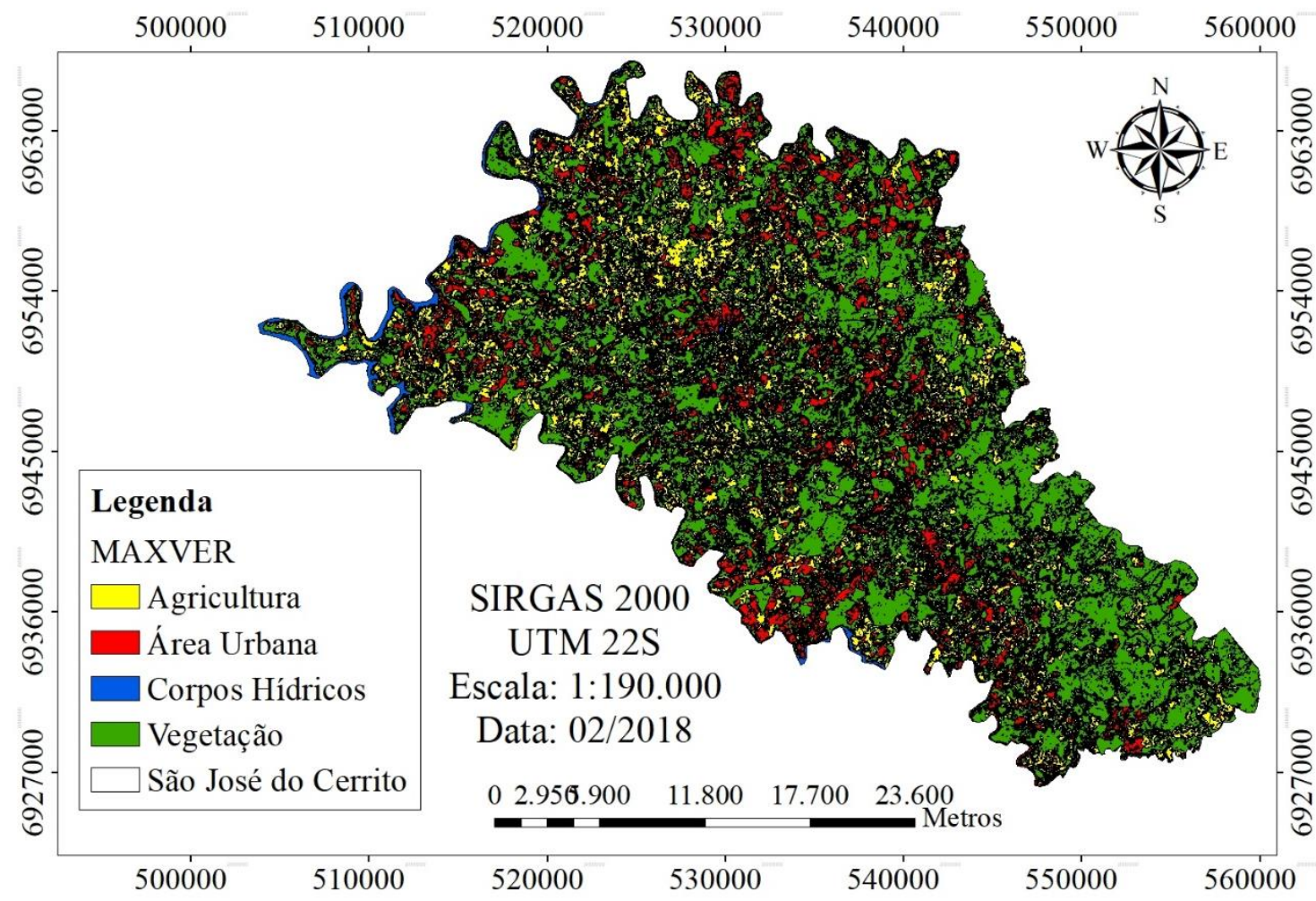

Figura 3. Classificação do uso e cobertura da terra do município de São José do Cerrito - SC pelo método MaxVer. 


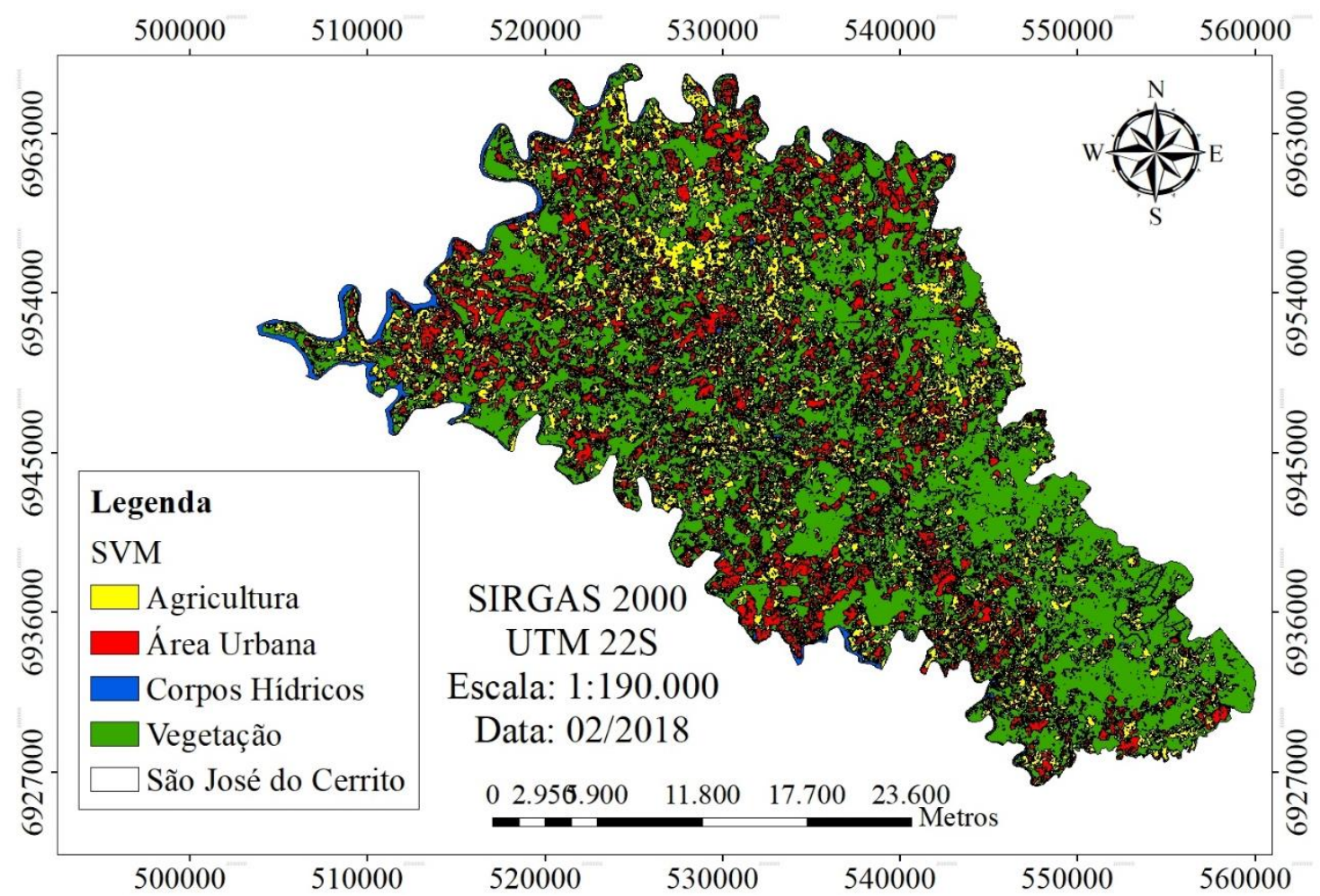

Figura 4. Classificação do uso e cobertura da terra do município de São José do Cerrito - SC pelo método SVM.

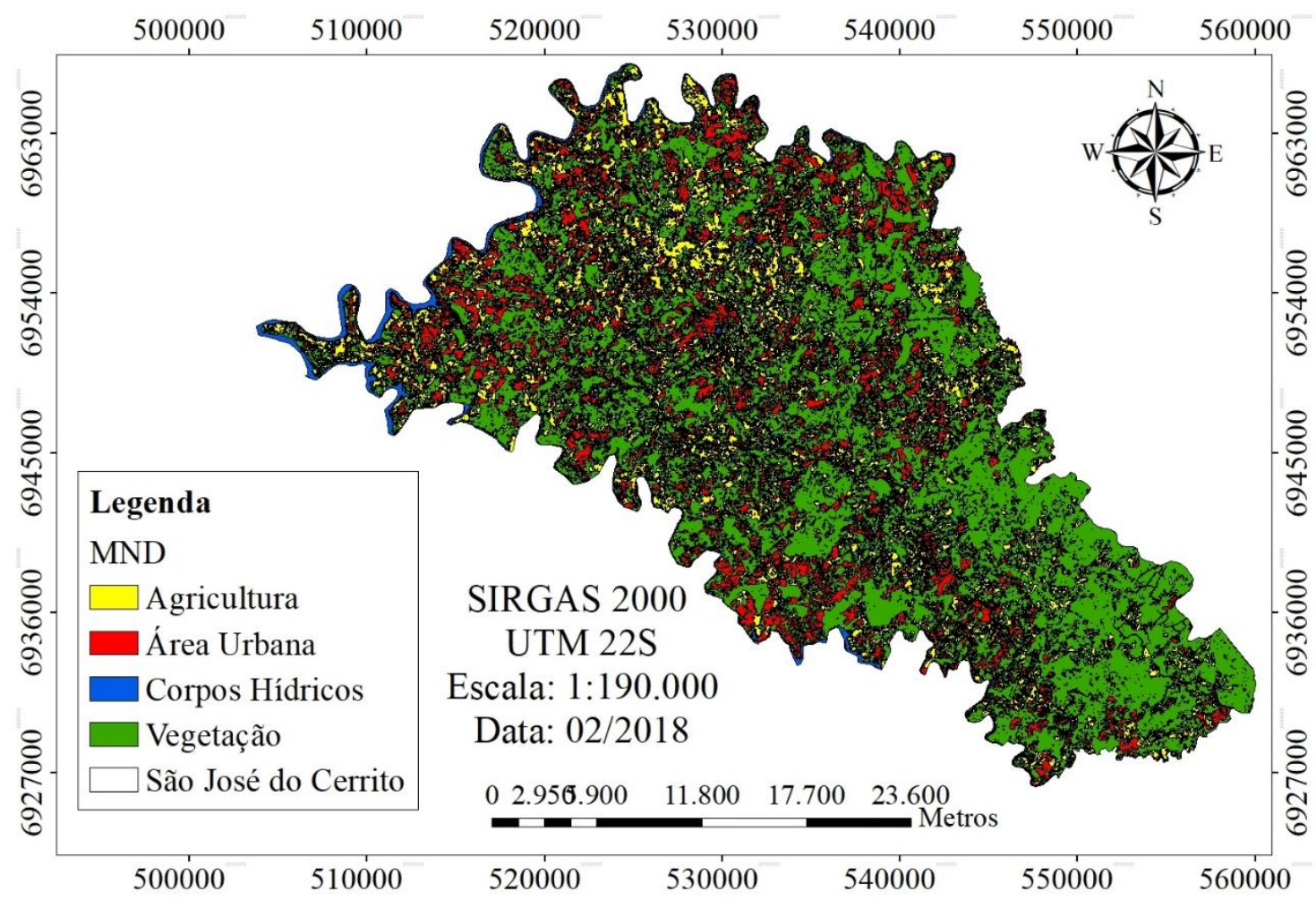

Figura 5. Classificação do uso e cobertura da terra do município de São José do Cerrito - SC pelo método MD.

A comparação entre classificadores supervisionados (RNA e MaxVer) em imagens Rapideye para mapear fragmentos florestais monodominados por Myracrodruon urundeuva em Tumiritinga, MG realizada por Oliveira et al. (2013) revelou que o melhor método foi o MaxVer.
A comparação de métodos de classificação supervisionada utilizando algoritmos de árvore de decisão com RNA e SVM no município de Mariana - MG foi investigada por Gaiad et al. (2017). Com índice Kappa de 0,979 e Exatidão Global de 0,9832, o SVM foi o algoritmo 
com o melhor desempenho. Já a classificação pelo MaxVer foi satisfatória no estudo de Marinho et al. (2017), no mapeamento das mudanças de classe e cobertura de solo em Sucupira - TO entre 2007 e 2017, o MaxVer obteve índice Kappa de 0,97 para 2007 e 0,99 para 2017.

Os resultados encontrados nessa pesquisa estão em concordância com as pesquisas citadas. Contudo, alguns fatores podem ter influenciado no desempenho dos métodos testados, como: resolução espacial, quantidade e qualidade das amostras de treinamento e validação geradas.

Além disso, alta resolução radiométrica de uma imagem pode aumentar a probabilidade de avaliação dos fenômenos com exatidão utilizando Sensoriamento Remoto, de acordo com Jensen (2011). Nesta pesquisa, a utilização de imagens oriundas da missão de satélites Sentinel-2/MSI com resolução radiométrica de 12 bits e resolução espacial de 10 metros derivou resultados satisfatórios para a classificação do uso e cobertura da terra do município de São José do Cerrito - SC. Apesar dos bons dados gerados, recomenda-se o fortalecimento da metodologia apresentada com sensores de alta resolução espacial e outras técnicas de classificação, como a orientada a objeto (Object-Based Image Analysis), para redução dos erros e gerar resultados precisos e aplicáveis para a gestão das áreas analisadas.

\section{CONCLUSÕES}

Os métodos de classificação supervisionada apresentaram resultados satisfatórios para mapeamento de uso da terra do município de São José do Cerrito - SC.

Para a gestão de um município e de seus recursos naturais, recomenda-se o uso de sensores com maior resolução espacial, bem como a utilização de outros métodos de classificação digital, como classificação orientada a objeto.

Também podem ser citados a amostragem de alvos a campo ou o uso de imagem de alta resolução como verdade de campo. Métodos de comparação multitemporal de imagens podem contribuir com resultados expressivos para avaliar o desenvolvimento e as mudanças na paisagem do local.

\section{REFERÊNCIAS}

ALVARES, C.A. et al. Koppen's climate classification map for Brazil. Meteorologische Zeitschrift, v.22, n.6, p.711-728, 2013.

ANDERSON, L.O. Classificação e monitoramento da cobertura vegetal do mato grosso utilizando dados multitemporais do sensor MODIS. São José dos Campos: INPE, 2004.

ARRUDA, G.P.D. et al. Mapeamento digital de solos por redes neurais artificiais com base na relação solo-paisagem. Revista Brasileira de Ciência do Solo, v.37, n.2, p.327-338, 2013.

CHAGAS, C.S. et al. Utilização de redes neurais artificiais na classificação de níveis de degradação em pastagens. Revista Brasileira de Engenharia Agrícola e Ambiental, v.13, n.3, p.319327, 2009.

CONGALTON, R.G. A review of assessing the accuracy of classifications of remotely sensed data. Remote Sensing of Environment, v.49, n.12, p.1671-1678, 1991.

ESA - EUROPEAN SPACE AGENCY. GMES Sentinel-2 mission required document. 2010 . Disponível em: http://esamultimedia.esa.int/docs/GMES/Sentinel-2 MRD.pdf

ESA - EUROPEAN SPACE AGENCY. SNAP and Sentinel Toolboxes. Disponível em: http://step.esa.int/main/download/

ESRI - ENVIRONMENTAL SYSTEMS RESEARCH INSTITUTE. Inc. ArcGIS Professional GIS for the desktop, v. 10.4. Disponível em: http://desktop.arcgis.com/en/arcmap/

EXELIS. Visual information solutions. Disponível em: https://www.harrisgeospatial.com/SoftwareTechnology/ENVI.as $\mathrm{px}$

GAIAD, N.P. et al. Uso e cobertura da terra apoiados em algoritmos baseados em aprendizado de máquina: o caso de Mariana - MG. Enciclopédia Biosfera, v.14, n.25, p.1211-1220, 2017.

IBGE - INSTITUTO BRASILEIRO DE GEOGRAFIA E ESTATÍSTICA Manual técnico da vegetação brasileira. 3 ed. Rio de Janeiro: IBGE, 2013.

JENSEN, J.R. Sensoriamento remoto do ambiente: uma perspectiva em recursos terrestres. São José dos Campos: São José dos Campos: Parêntese Editora, 2011.

KAUFMAN, Y.J. et al. The MODIS $2.1 \mu \mathrm{m}$ channel - correlation with visible reflectance for use in remote sensing of aerosol. IEEE Transactions on Geoscience and Remote Sensing, v.35, p.12861298, 1997.

LANDIS, J.; KOCH, G.G. The measurements of agreement for categorical data. Biometrics, v.33, n.1, p.159-179, 1977.

LI, M. et al. A review of remote sensing image classification techniques: The role of spatio-contextual information. European Journal of Remote Sensing, v.47, n.1, p.389-411. 2014. 
LIMA, A. Influência da cobertura da terra na extensão e configuração espacial de áreas queimadas em anos de seca extrema na Amazônia Oriental. 2013. 82p. (Tese de doutorado).

MARINHO, P.H.A. et al. Classificação de imagem orbital pelo método máxima verossimilhança em Sucupira - TO. Agrarian Academy, v.4, n.7, p.115-124, 2017.

OLIVEIRA, F.P et al. Mapeamento de fragmentos florestais com monodominância de aroeira a partir da classificação supervisionada de imagens Rapideye. Revista Árvore, v.37, n.1, p.151-161, 2013.

REX, F.E. et al. Potencial de imagens MSI (Sentinel-2) para classificação do uso e cobertura da terra. Enciclopédia Biosfera, v.15, n.27, p.219-231, 2018.

ROSAN, T.M.; ALCÂNTARA, E. Detecção de mudanças de uso e cobertura da terra na Amazônia Legal Matogrossense: o estudo de caso do município de Cláudia (MT). Revista Brasileira de Cartografia, n.68/5, p.979-990, 2016.

SOARES FILHO, B.S. Fragmentação da paisagem florestal em função da estrutura e dinâmica fundiária no norte do Mato Grosso. 10 Simpósio Brasileiro de Sensoriamento Remoto, p.987-995, 2001

ZHU, Z. et al. Assessment of spectral, polarimetric, temporal, and spatial dimensions for urban and peri-urban land cover classification using Landsat and SAR data. Remote Sensing of Environment, v.117, p.72-82, 2012. 